\title{
Changes in sexual behaviour, anxiety symptoms, and quality of couple relationship of patients with infertility during the COVID-19 lockdown
}

\author{
Meng Dong ${ }^{1,2,3} \cdot$ Yanqiang Tao ${ }^{4}$ Shanshan $\mathrm{Wu}^{1,2} \cdot$ Lin Kong $^{1,2} \cdot$ Feifei Zhou ${ }^{1,2} \cdot$ Jichun Tan $^{1,2}$ (1)
}

Received: 20 September 2021 / Accepted: 16 November 2021 / Published online: 30 January 2022

(c) The Author(s), under exclusive licence to Springer Science+Business Media, LLC, part of Springer Nature 2021

\begin{abstract}
Purpose This study aimed to explore the perceived changes in sexual behaviour during COVID-19 lockdown, anxiety symptoms, and couple relationship of patients with infertility.

Methods We performed an observational cross-sectional study between 20 November 2020 and 15 January 2021. We used stratified analysis of different stress levels and Quality of Marriage Index (QMI) scores to compare the perceived changes in sexual behaviour, anxiety symptoms, and couple relationship. The logistic regression model was performed to assess factors correlated with couples' relationship quality during the lockdown. Furthermore, we performed pathway analyses to assess whether the changes in sexual behaviour, stress level, or psychological anxiety during the lockdown could predict the quality of couple relationship.

Results A total of 940 patients with infertility were included in this study. When we conducted a stratified analysis of the participants, significant differences were found between the changes in their sexual behaviour, stress levels, and couple relationship quality. The logistic regression model showed that sex, anxiety symptoms, decreased sexual satisfaction, sexual activity frequency, and income levels were closely related to couple relationship quality. Pathway analyses indicated that changes in their sexual behaviour, anxiety symptoms, and stress levels could all predict the quality of couple relationship. Conclusions The perceived changes in sexual behaviour with different stress levels and couple relationship quality showed significant differences. Analysing the related factors that affect the quality of couple relationship, especially in times of crisis, is of great significance as this information can contribute to the improvement of treatment for patients with infertility.
\end{abstract}

Keywords COVID-19 $\cdot$ Infertility $\cdot$ Sexual behaviour $\cdot$ Couple relationship $\cdot$ Stress $\cdot$ Anxiety

\section{Introduction}

The coronavirus disease 2019 (COVID-19) pandemic has brought unprecedented challenges to the world. Currently, researchers are mainly focussing on health hazards

Jichun Tan

tjczjh@163.com

Meng Dong

494108809@qq.com

Yanqiang Tao

psyxuele2020@163.com

Shanshan $\mathrm{Wu}$

2949535864@qq.com

Lin Kong

49485714@qq.com

Feifei Zhou

726598782@qq.com associated with COVID-19 infection, COVID-19 treatment, and vaccine development [1-3]. Nevertheless, we must not ignore the effect of the pandemic on different aspects of people's lives. Many studies have confirmed that COVID19 has severely affected people's mental and psychological

1 Center of Reproductive Medicine, Shengjing Hospital of China Medical University, No. 39 Huaxiang Road, Tiexi District, Shenyang 110072, Liaoning Province, China

2 Key Laboratory of Reproductive Dysfunction Diseases and Fertility Remodelling of Liaoning Province, No. 39 Huaxiang Road, Tiexi District, Shenyang 110072, Liaoning Province, China

3 School of Life Sciences, China Medical University, No. 77 Puhe Road, Shenbei New District, Shenyang 110122, Liaoning Province, China

4 Faculty of Psychology, Beijing Key Laboratory of Applied Experimental Psychology, Beijing Normal University, No. 19 Xinjiekou Wai Street, Haidian District, Beijing 10085, China 
health [4-10]. Sexual activity is an essential part of life [11], and sexual health is an important indicator of the quality of life, which is a vital aspect of well-being [12-14]. Anxiety, lack of privacy, fear of health conditions, and psychosomatic symptoms caused by lockdown can affect the quality of sexual life [15]. Studies based on changes in sexual activity due to the lockdowns enforced in different populations and countries have reported different conclusions. One study showed that overall sexual activity, sexual activity frequency, and risky behaviours declined significantly among young populations in China [16]. Some female participants in Italy reported a decrease in pleasure, satisfaction, desire, and arousal during lockdown [16]. However, a survey conducted among the individuals of three southeast Asian countries revealed that the frequency of sexual activity of couples had increased considerably when compared to the frequency before the lockdown [17]; similar results were found among Turkish women [18]. Based on the above observations, an investigation into the changes in sexual behaviour of patients with infertility during lockdown could be meaningful because sexual health issues of couples with infertility need to be given increased attention due to the societal implications of the condition. However, there is currently no research documenting changes in the sexual behaviour of couples with infertility during the COVID-19 pandemic.

Infertility is defined as failure to achieve a successful pregnancy after 12 months, or more, of regular, unprotected sexual intercourse [19]. Infertility is a multidimensional stressor, and the treatment itself and the unpredictable treatment outcomes are likely to evoke feelings of psychological distress [20]. Indeed, one study found that $56 \%$ of patients with infertility scored in the clinical range for depression and $76 \%$ for anxiety [21]. Patients with infertility may be more sensitive and vulnerable in the face of stress and crisis [22]. Published data indicate that the interruption of fertility care due to COVID-19 led to psychological distress in patients with infertility [22-24]. A recent study indicated that $64 \%$ of the participants experienced psychological distress during treatment suspension; feeling helpless following the suspension of treatment was also associated with higher distress [22]. Based on the psychological symptoms caused by lockdown, it is expected that sexual behaviour would also be affected [25].

Several studies have verified the correlation between psychological health and couple relationship quality [26-28]. During the COVID-19 pandemic, individuals with poor couple relationship quality were more burdened than those with good couple relationship quality, and the prevalence of depression increased from $13 \%$ up to $35 \%$ based on couple relationship quality [27].

Based on the above research, our specific hypotheses are that the COVID-19 pandemic may aggravate the psychological anxiety and stress level of patients with infertility, resulting in changes in sexual behaviour, thereby further affecting the couple relationship quality. However, to date, no study on the changes in sexual behaviour and the quality of couple relationship of patients with infertility during the COVID-19 pandemic has been conducted. Thus, this study aimed to determine whether the COVID19 pandemic has had an impact on the changes in sexual behaviour and couple relationship of patients with infertility and investigate the related factors that affect couple relationship quality.

\section{Materials and methods}

\section{Procedure}

This cross-sectional study was conducted at the Centre of Reproductive Medicine, Shenyang, China. Patients diagnosed with infertility were invited to participate in the study when they visited the outpatient clinic of the Reproductive Medicine Centre. The research process was as follows: First, the patients provided consent to participate in this anonymous research; then, the nurse led the participants to a private room of the clinic reserved for filling out questionnaires. All participants provided written informed consent prior to starting the study.

\section{Participants}

All participants were recruited from the Centre of Reproductive Medicine and were undergoing infertility treatments. Of the 1158 respondents in this study, 218 failed to complete all questions and were excluded. Thus, the responses of 940 participants were included in the analyses (response rate, $81.17 \%$ ). Table 1 shows the participants' demographic characteristics. The average age was $32.73 \pm 4.55$ years for female participants and $33.57 \pm 4.44$ years for male participants. The average infertility duration was $4.12 \pm 3.06$ years for female participants and $3.70 \pm 2.88$ years for male participants (Table 1).

The inclusion criteria were as follows: female or male diagnosed with infertility or sterility and has not yet undergone assisted reproductive technology treatment, such as in vitro fertilisation-embryo transfer; aged between 21 and 45 years; married and are living with their spouses. This study is part of a large-scale crosssectional study on the sexual health of patients with infertility during the COVID-19 pandemic. To avoid the bias caused by age and endocrine factors on sexual function and sexual health, this study only included people younger than 45 and excluded some causes of infertility that were reported to have affected sexual functions. The 
Table 1 Demographic characteristics of the study population $(n=940)$

\begin{tabular}{|c|c|c|}
\hline Characteristics & $\begin{array}{l}\text { Female }(n=611,65.00 \%) \\
\text { Mean } \pm \mathrm{SD} / n(\%)\end{array}$ & $\begin{array}{l}\text { Male }(n=329,35.00 \%) \\
\text { Mean } \pm \mathrm{SD} / n(\%)\end{array}$ \\
\hline Age (years) & $32.73 \pm 4.55$ & $33.57 \pm 4.44$ \\
\hline $\operatorname{BMI}\left(\mathrm{kg} / \mathrm{m}^{2}\right)$ & $23.48 \pm 3.39$ & $25.83 \pm 4.09$ \\
\hline$<18.5$ & $32(5.23)$ & $6(1.82)$ \\
\hline $18.5-25$ & $388(63.50)$ & 137 (41.64) \\
\hline $25-30$ & $161(26.35)$ & $134(40.73)$ \\
\hline$\geq 30$ & $30(4.91)$ & $52(15.81)$ \\
\hline \multicolumn{3}{|l|}{ Smoking status } \\
\hline Smoker & $30(4.91)$ & 145 (44.07) \\
\hline Non-smoker & $581(95.09)$ & $184(55.93)$ \\
\hline \multicolumn{3}{|c|}{ Annual income (ten thousand yuan) } \\
\hline$<5$ & $320(52.37)$ & $106(32.22)$ \\
\hline $5-10$ & $163(26.68)$ & 125 (37.99) \\
\hline $10-15$ & $67(10.97)$ & $47(14.29)$ \\
\hline $15-20$ & $28(4.58)$ & $23(6.99)$ \\
\hline$>20$ & $33(5.40)$ & $28(8.51)$ \\
\hline \multicolumn{3}{|l|}{ Education } \\
\hline$\leq$ High school & $214(35.02)$ & $121(36.78)$ \\
\hline Specialised college & $161(26.35)$ & $83(25.23)$ \\
\hline Undergraduate & $190(31.10)$ & $106(32.22)$ \\
\hline$\geq$ Postgraduate & $46(7.53)$ & $19(5.78)$ \\
\hline Duration of infertility (years) & $4.12 \pm 3.06$ & $3.70 \pm 2.88$ \\
\hline \multicolumn{3}{|l|}{ Cause of infertility } \\
\hline Tubal factor & $308(50.41)$ & - \\
\hline Ovulation disorders & $120(19.64)$ & - \\
\hline Unexplained & $50(8.18)$ & - \\
\hline Combined factor & 133 (21.77) & \\
\hline Male factor & - & $329(100.00)$ \\
\hline
\end{tabular}

$S D$, standard deviation; $B M I$, body mass index exclusion criteria were as follows: females diagnosed with endometriosis and premature ovarian failure; male with severe male infertility, such as azoospermia; patients with diabetes and high blood pressure; patients with genital tract abnormalities and genitourinary infections; ingesting drugs that may affect sexual function and/or mental state (selective serotonin reuptake inhibitors, tricycle antidepressants, and phosphodiesterase type 5 inhibitors) [28]; clinically diagnosed sexual dysfunction prior to infertility diagnosis; and psychiatric conditions (that can cause sexual dysfunction).

\section{Measures}

We used a self-designed questionnaire and three standardised questionnaires (Supplementary 1 and 2) to evaluate the perceived changes in sexual behaviour, stress levels, anxiety symptoms, and quality of couple relationship of patients with infertility during the COVID-19 pandemic. All questionnaires were validated in the Chinese language.

\section{Demographic information}

The following baseline information was collected: age, body mass index, economic level, infertility duration, education level, and smoking status. An additional question on income changes during the COVID-19 pandemic was also included: How has the COVID-19 pandemic affected your annual income? Answer as increased, unchanged, or decreased.

\section{Perceived changes in sexual behaviour}

A self-designed questionnaire focused on changes in sexual behaviour during the COVID-19 lockdown was administered. The following questions were included: (1) Compared with that before the COVID-19 pandemic, how has your sexual desire changed? (item 1); (2) Compared with that before 
the COVID-19 pandemic, how has your sexual intercourse frequency changed? (item 2); (3) Compared with that before the COVID-19 pandemic, how has your sexual satisfaction changed? (item 3) (The options to answer the above three questions were set as increased, unchanged, or decreased.); (4) How has your frequency of masturbation changed compared with that before the COVID-19 pandemic? (item 4); (5) How has your frequency of watching pornography changed compared with that before the COVID-19 pandemic? (item 5) (The answers to the above two questions were set as none, increased, unchanged, or decreased).

\section{Psychological anxiety}

Anxiety symptoms were evaluated using the 7-item Generalized Anxiety Disorder scale (GAD-7). The items are scored on a 4-point scale, from 0 to 3 , and the total score ranges from 0 to 21 . The cut-off score of $\geq 10$ was used to assess the presence of anxiety [29]. A question on COVID-19-related anxiety was also included: Has the COVID-19 pandemic increased/affected your anxiety levels? (answer as no, mildly, or extremely).

\section{Stress levels}

Stress levels were evaluated using the 14-item Perceived Stress Scale (PSS-14) [30]. The items are scored on a 5-point scale, from 1 to 5 , and the total score ranges from 14 to 70 . The perceived stress level was based on the PSS-14 score, with the severity of stress represented as follows: 14-28, low; 29-42, general; 43-56, high; and 57-70, very high. The Cronbach alfa values were set between 0.81 and 0.86 [30].

\section{Couple relationship quality}

The third part was the Quality of Marriage Index questionnaire, a 6-item scale designed to evaluate couple relationship quality. The first five items were scored on a 7-point scale ranging from 1 (strongly disagree) to 7 (strongly agree). The sixth item was scored on a 10-point scale ranging from 1 (extremely low) to 10 (extremely high). The total score ranged from 6 to 45 points. A QMI cut-off value of $<34$ indicated poor quality of relationship, with sensitivity of $88 \%$ and specificity of $85 \%$. The QMI demonstrates good item characteristics and excellent reliability $(\alpha=0.94)$ [31, 32]. A question regarding changes in couple relationship during the COVID19 pandemic was also included: Compared with that before the COVID-19 pandemic, how has your relationship as a couple changed? (answer as better, unchanged, or deteriorated).

\section{Statistical analyses}

Data analysis was performed using the statistical software SPSS (version 22.0; IBM Corp., Armonk, NY, USA) and the package of Lavaan [33] in R. The chi-square test, independent $t$-test, one-way analysis of variance (ANOVA), and logistic regression model were performed using SPSS. The principal component analysis (PCA), confirmatory factor analysis (CFA), and pathway analyses were performed in $\mathrm{R}$. Results were presented in a tabular format. Categorical variables were summarised as counts and percentages, and continuous measures were summarised as counts, means, and standard deviations (SDs).

We used a PCA to test the validation of changes in sexual behaviour. Factorability of the polychoric correlation matrix was assessed by Bartlett's Test of Sphericity [34] and KMO value $\geq 0.70$ [35]. A CFA was used to validate the structure of changes in sexual behaviour. To assess model fit, Chi-square divided by its degree of freedom $\left(\chi^{2} / \mathrm{df}\right)$, Tucker Lewis Index (TLI), Comparative Fit Index (CFI), and Root Mean Square Error of Approximation (RMSEA) were used. Model fit was considered adequate according to the following criteria: $\chi^{2} / \mathrm{df} \leq 3$; CFI and TLI $\geq 0.90$ (preferably $\geq 0.95$ ); RMSEA $\leq 0.08[36,37]$.

The chi-square test, independent $t$-test, and ANOVA were used to compare the changes in sexual activity, stress level, anxiety symptoms, and couple relationship quality during the lockdown. Moreover, a stratified analysis was performed according to stress levels and QMI score, and the differences among the groups were compared. Effect size was calculated to evaluate the strength of each statistical analysis and measured with Cohen's $d$ for the independent $t$-test, Cramer's $V$ for the chi-squared test, and $\eta^{2}$ for the ANOVA. A logistic regression model was employed to explore the factors that were related to couple relationship quality by adjusting for all possible confounders during the lockdown. The $p$-value, odds ratio (OR), and $95 \%$ confidence interval (CI) were evaluated, and a two-tailed $p$-value of $<0.05$ indicated statistical significance. We performed pathway analyses to assess whether the changes in sexual behaviour during the lockdown, stress levels, and psychological anxiety could predict the quality of couple relationship.

\section{Results}

\section{Principal components analysis and confirmatory factor analysis}

We conducted the CFA with five items, as listed in "Perceived changes in sexual behaviour." All items loaded sufficiently, ranging from 0.79 to 0.91 , and we divided the five items into two factors: factor 1 (item 1, item 2, and item 3) and factor 2 (item 4 and item 5). Factor 1 accounted for $45.06 \%$ of the common variance; factor 2 accounted for $29.58 \%$ of the common variance; the total 
Table 2 The principal component analysis (PCA)

\begin{tabular}{|c|c|c|c|}
\hline Items & Factor1 loading & Factor2 loading & $h^{2}$ \\
\hline $\begin{array}{l}\text { 1. Compared with that before the COVID-19 pandemic, how } \\
\text { has your sexual desire changed? }\end{array}$ & 0.91 & & 0.80 \\
\hline $\begin{array}{l}\text { 2. Compared with that before the COVID-19 pandemic, how } \\
\text { has your sexual intercourse frequency changed? }\end{array}$ & 0.89 & & 0.83 \\
\hline $\begin{array}{l}\text { 3. Compared with that before the COVID-19 pandemic, how } \\
\text { has your sexual satisfaction changed? }\end{array}$ & 0.79 & & 0.62 \\
\hline $\begin{array}{l}\text { 4. How has your frequency of masturbation changed compared } \\
\text { with that before the COVID-19 pandemic? }\end{array}$ & & 0.86 & 0.74 \\
\hline $\begin{array}{l}\text { 5. How has your frequency of watching pornography changed } \\
\text { compared with that before the COVID- } 19 \text { pandemic? }\end{array}$ & & 0.86 & 0.74 \\
\hline Eigenvalues & 2.25 & 1.48 & \\
\hline$\%$ of common variance & 45.06 & 29.58 & \\
\hline$\%$ of total variance & 74.64 & & \\
\hline Cronbach's alpha & 0.83 & 0.65 & \\
\hline
\end{tabular}

$h^{2}=$ communality

variance was $74.64 \%$ (Table 2). Following these results, a two-factor solution with five items was accepted as an adequate representation of the factor structure for changes in sexual behaviour. The goodness-of-fit of the two-factor solution was acceptable, $\chi^{2} / \mathrm{df}=4.68, \mathrm{CFI}=0.99$, TLI $=$ 0.98 , RMSEA $=0.06$. These results show that the CFA confirmed the factor structure of the scale of sexual behaviour. The Cronbach's alpha for each factor was 0.83 and 0.65 , respectively.

\section{Changes in sexual behaviour, stress levels, anxiety symptoms, and couple relationship quality of patients with infertility during lockdown}

Among the participants, $4.75 \%$ females and $4.26 \%$ males perceived an increase in sexual satisfaction during the lockdown, while $5.89 \%$ females and $10.33 \%$ males perceived a decrease in sexual satisfaction; there was a significant difference between the two groups $(p<0.05)$. Also, $4.42 \%$ females and $5.78 \%$ males experienced an increase in sexual desire, while $10.31 \%$ females and $9.42 \%$ males experienced a decrease in sexual desire during the lockdown $(p>0.05) ; 5.73 \%$ females and $5.78 \%$ males reported an increase in sexual activity frequency, while $10.64 \%$ females and $13.07 \%$ males reported a decrease in sexual activity frequency $(p>0.05)$. Moreover, males experienced an $11.85 \%$ increase and a $19.45 \%$ decrease in changes in masturbation frequency, while females experienced a $10.47 \%$ increase and a $9.49 \%$ decrease in changes in masturbation frequency in comparison with the pre-lockdown period $(p<0.01)$. For changes in pornography use, males experienced a $9.42 \%$ increase and a $10.64 \%$ decrease, while females experienced a $7.36 \%$ increase and a $7.36 \%$ decrease $(p<0.01)$. The above results revealed that the overall sexual behaviour of most participants had not changed significantly (Table 3).
The GAD-7 score for females was significantly lower than that for males $(p<0.05)$. Regarding COVID-19-related anxiety symptoms, $3.44 \%$ females and $5.17 \%$ males reported extreme COVID-19-related anxiety, while $16.69 \%$ females and $33.13 \%$ males reported mild COVID-19-related anxiety $(p<0.01)$. The QMI score for females was significantly lower than that for males $(p<0.01)$. Regarding couple relationship during the lockdown, $17.18 \%$ females and $17.93 \%$ males reported an improvement in couple relationship during the lockdown, while $3.11 \%$ females and $4.56 \%$ males reported a deterioration of couple relationship $(p>0.05)$. The PSS-14 score for females was significantly lower than that for males $(p<0.01)$, and males had higher stress levels than females $(p<0.01)$ (Table 3$)$.

\section{Stratified analysis of stress levels and QMI score for the changes in sexual behaviour, anxiety symptoms, and couple relationship during lockdown}

We divided the participants into four groups according to the PSS-14 score: very high $(n=67)$, high $(n=188)$, general ( $n$ $=499)$, and low $(n=186)$. For changes in sexual activity, the chi-square test showed that the changes in sexual satisfaction, sexual desire, sexual activity frequency, and pornography use demonstrated significant differences among the four groups $(p<0.01)$. The changes in the frequency of masturbation had no significant differences among the four groups $(p>0.05)$. The GAD-7 score and QMI score were significantly different among the four groups $(p<0.01)$ (Table 4$)$.

On the other hand, we divided the patients into two groups according to the QMI score: QMI $\geq 34(n=296)$; QMI $<34(n=644)$. The PSS-14 score in the low-quality relationship group was significantly higher than in the highquality relationship group $(p<0.01)$. The changes in sexual behaviour, including sexual satisfaction, sexual desire, 
Table 3 Changes in sexual behaviour, couple relationship, and anxiety symptoms of patients with infertility during lockdown ( $n=940)$

\begin{tabular}{|c|c|c|c|c|c|c|}
\hline Items & $\begin{array}{l}\text { Total }(n=940) \\
n(\%) / \text { mean } \pm \mathrm{SD}\end{array}$ & $\begin{array}{l}\text { Female }(n=611) \\
n(\%) / \text { mean } \pm \mathrm{SD}\end{array}$ & $\begin{array}{l}\text { Male }(n=329) \\
n(\%) / \text { mean } \pm \mathrm{SD}\end{array}$ & Statistics & Effect size $(V / d)$ & $P$-value \\
\hline \multicolumn{4}{|c|}{ Changes in sexual satisfaction } & $\chi^{2}=6.16$ & $V=0.08$ & 0.04 \\
\hline Increased & $43(4.57)$ & $29(4.75)$ & $14(4.26)$ & & & \\
\hline Unchanged & $827(87.98)$ & $546(89.36)$ & $281(85.41)$ & & & \\
\hline Decreased & $70(7.45)$ & $36(5.89)$ & $34(10.33)$ & & & \\
\hline \multicolumn{4}{|c|}{ Changes in sexual desire } & $\chi^{2}=0.98$ & $V=0.03$ & 0.62 \\
\hline Increased & $46(4.89)$ & $27(4.42)$ & $19(5.78)$ & & & \\
\hline Unchanged & $800(85.11)$ & $521(85.27)$ & $279(84.80)$ & & & \\
\hline Decreased & $94(10.00)$ & $63(10.31)$ & $31(9.42)$ & & & \\
\hline \multicolumn{4}{|c|}{ Changes in sexual frequency } & $\chi^{2}=1.26$ & $V=0.04$ & 0.53 \\
\hline Increased & $54(5.74)$ & $35(5.73)$ & $19(5.78)$ & & & \\
\hline Unchanged & $778(82.77)$ & $511(83.63)$ & $267(81.15)$ & & & \\
\hline Decreased & 108 (11.49) & $65(10.64)$ & $43(13.07)$ & & & \\
\hline \multicolumn{4}{|c|}{ Changes in frequency of masturbation } & $\chi^{2}=83.70$ & $V=0.30$ & $<0.01$ \\
\hline Increased & $103(10.96)$ & $64(10.47)$ & $39(11.85)$ & & & \\
\hline Unchanged & $384(40.85)$ & $212(34.70)$ & $172(52.28)$ & & & \\
\hline Decreased & $122(12.98)$ & $58(9.49)$ & $64(19.45)$ & & & \\
\hline None & $331(35.21)$ & $277(45.34)$ & $54(16.41)$ & & & \\
\hline \multicolumn{4}{|c|}{ Changes in frequency of pornography use } & $\chi^{2}=64.69$ & $V=0.26$ & $<0.01$ \\
\hline Increased & $76(8.09)$ & $45(7.36)$ & $31(9.42)$ & & & \\
\hline Unchanged & $311(33.09)$ & $156(25.53)$ & $155(47.11)$ & & & \\
\hline Decreased & $80(8.51)$ & $45(7.36)$ & $35(10.64)$ & & & \\
\hline None & $473(50.32)$ & $365(59.74)$ & $108(32.83)$ & & & \\
\hline GAD-7 score & $6.58 \pm 2.82$ & $6.18 \pm 2.59$ & $7.33 \pm 3.07$ & $t=-6.11$ & $d=-0.42$ & $<0.01$ \\
\hline \multicolumn{4}{|c|}{ COVID-19-related anxiety } & $\chi^{2}=36.92$ & $V=0.20$ & $<0.01$ \\
\hline Extremely & $38(4.04)$ & $21(3.44)$ & $17(5.17)$ & & & \\
\hline Mildly & $211(22.45)$ & $102(16.69)$ & $109(33.13)$ & & & \\
\hline No & $691(73.51)$ & $488(79.87)$ & $203(61.70)$ & & & \\
\hline \multicolumn{4}{|c|}{ Changes in income during lockdown } & $\chi^{2}=5.35$ & $V=0.08$ & 0.07 \\
\hline Increased & $16(1.70)$ & $10(1.64)$ & $6(1.82)$ & & & \\
\hline Unchanged & $450(47.87)$ & $276(45.17)$ & $174(52.89)$ & & & \\
\hline Decreased & $474(50.43)$ & $325(53.19)$ & $149(45.29)$ & & & \\
\hline QMI score & $30.62 \pm 6.30$ & $29.37 \pm 5.68$ & $32.93 \pm 6.73$ & $t=-8.57$ & $d=-0.59$ & $<0.01$ \\
\hline \multicolumn{4}{|c|}{ Changes in couple relationship during lockdown } & $\chi^{2}=1.44$ & $V=0.04$ & 0.49 \\
\hline Better & $164(17.45)$ & $105(17.18)$ & $59(17.93)$ & & & \\
\hline Unchanged & 742 (78.94) & $487(79.71)$ & $255(77.51)$ & & & \\
\hline Deteriorated & $34(3.62)$ & $19(3.11)$ & $15(4.56)$ & & & \\
\hline PSS-14 score & $36.48 \pm 11.69$ & $35.35 \pm 10.91$ & $38.57 \pm 12.77$ & $t=-4.07$ & $d=-0.28$ & $<0.01$ \\
\hline \multicolumn{4}{|l|}{ Stress level } & $\chi^{2}=15.40$ & $V=0.13$ & $<0.01$ \\
\hline Very high & $67(7.13)$ & $33(5.40)$ & $34(10.33)$ & & & \\
\hline High & $188(20.00)$ & $112(18.33)$ & $76(23.10)$ & & & \\
\hline General & 499 (53.09) & $330(54.01)$ & $169(51.37)$ & & & \\
\hline Low or none & $186(19.79)$ & $136(22.26)$ & $50(15.20)$ & & & \\
\hline
\end{tabular}

GAD-7, Generalized Anxiety Disorder scale-7; QMI, Quality of Marriage Index; PSS-14, Perceived Stress Scale-14

and sexual activity frequency, were significantly different between the two groups $(p<0.01)$. Moreover, the GAD-7 score in the low-quality relationship group was significantly higher than that in the high-quality relationship group ( $p<$ 0.01) (Table 5).

\section{Factors that correlated with couple relationship quality determined by the logistic regression model}

An analysis of the relevant factors associated with couple relationship quality using the logistic regression model 
Table 4 Changes in sexual behaviour, couple relationship, and anxiety symptoms of participants among different stress levels groups during lockdown $(n=940)$

\begin{tabular}{|c|c|c|c|c|c|c|c|}
\hline Items & $\begin{array}{l}\text { Very high }(n=67) \\
\text { mean } \pm \mathrm{SD} / n(\%)\end{array}$ & $\begin{array}{l}\text { High }(n=188) \\
\text { mean } \pm \mathrm{SD} / n(\%)\end{array}$ & $\begin{array}{l}\text { General }(n=499) \\
\text { mean } \pm \mathrm{SD} / n(\%)\end{array}$ & $\begin{array}{l}\text { Low }(n=186) \\
\text { mean } \pm \mathrm{SD} / n(\%)\end{array}$ & Statistics & Effect size $\left(\eta^{2} / V\right)$ & $\overline{P \text {-value }}$ \\
\hline \multicolumn{5}{|c|}{ Changes in sexual satisfaction } & $\chi^{2}=20.93$ & $V=0.11$ & $<0.01$ \\
\hline Increased & $4(5.97)$ & $8(4.26)$ & $17(3.41)$ & $14(7.53)$ & & & \\
\hline Unchanged & $50(74.63)$ & $168(89.36)$ & 449 (89.98) & $160(86.02)$ & & & \\
\hline Decreased & $13(19.40)$ & $12(6.38)$ & $33(6.61)$ & $12(6.45)$ & & & \\
\hline \multicolumn{5}{|c|}{ Changes in sexual desire } & $\chi^{2}=39.69$ & $V=0.15$ & $<0.01$ \\
\hline Increased & $3(4.48)$ & $8(4.26)$ & $15(3.01)$ & $20(10.75)$ & & & \\
\hline Unchanged & $47(70.15)$ & $157(83.51)$ & $443(88.78)$ & $153(82.26)$ & & & \\
\hline Decreased & $17(25.37)$ & $23(12.23)$ & $41(8.22)$ & $13(6.99)$ & & & \\
\hline \multicolumn{5}{|c|}{ Changes in sexual frequency } & $\chi^{2}=21.72$ & $V=0.11$ & $<0.01$ \\
\hline Increased & $5(7.46)$ & $9(4.79)$ & $21(4.21)$ & $19(10.22)$ & & & \\
\hline Unchanged & $47(70.15)$ & $152(80.85)$ & $430(86.17)$ & $149(80.11)$ & & & \\
\hline Decreased & $15(22.39)$ & $27(14.36)$ & $48(9.62)$ & $18(9.68)$ & & & \\
\hline \multicolumn{5}{|c|}{ Changes in frequency of masturbation } & $\chi^{2}=13.04$ & $V=0.07$ & 0.16 \\
\hline Increased & $12(17.92)$ & $24(12.77)$ & $43(8.62)$ & $24(12.90)$ & & & \\
\hline Unchanged & $30(44.78)$ & $74(39.36)$ & $200(40.08)$ & $80(43.01)$ & & & \\
\hline Decreased & $7(10.45)$ & $30(15.96)$ & $65(13.03)$ & $20(10.75)$ & & & \\
\hline None & $18(26.87)$ & $60(31.91)$ & $191(38.28)$ & $62(33.33)$ & & & \\
\hline \multicolumn{5}{|c|}{ Changes in frequency of pornography use } & $\chi^{2}=31.73$ & $V=0.11$ & $<0.01$ \\
\hline Increased & $12(17.91)$ & $14(7.45)$ & $32(6.41)$ & $18(9.68)$ & & & \\
\hline Unchanged & $30(44.78)$ & $61(32.45)$ & $156(31.26)$ & $64(34.41)$ & & & \\
\hline Decreased & $5(7.46)$ & $26(13.83)$ & $41(8.22)$ & $8(4.30)$ & & & \\
\hline None & $20(29.85)$ & $87(46.28)$ & $270(54.11)$ & $96(51.61)$ & & & \\
\hline GAD-7 score & $8.18 \pm 4.71$ & $6.47 \pm 2.89$ & $6.29 \pm 2.31$ & $6.89 \pm 2.89$ & $F=10.10$ & $\eta^{2}=0.03$ & $<0.01$ \\
\hline \multicolumn{5}{|c|}{ COVID-19-related anxiety } & $\chi^{2}=25.87$ & $V=0.12$ & $<0.01$ \\
\hline Extremely & $9(13.43)$ & $8(4.26)$ & $14(2.81)$ & $7(3.76)$ & & & \\
\hline Mildly & $16(23.88)$ & $53(28.19)$ & $112(22.44)$ & $30(16.13)$ & & & \\
\hline No & $42(62.69)$ & $127(67.55)$ & $373(74.75)$ & $149(80.11)$ & & & \\
\hline QMI score & $27.70 \pm 8.60$ & $30.71 \pm 5.96$ & $31.06 \pm 5.84$ & $30.39 \pm 6.60$ & $F=5.78$ & $\eta^{2}=0.02$ & $<0.01$ \\
\hline \multicolumn{5}{|c|}{ Changes in couple relationship during lockdown } & $\chi^{2}=43.32$ & $V=0.15$ & $<0.01$ \\
\hline Better & $13(19.40)$ & $21(11.17)$ & $97(19.44)$ & $33(17.74)$ & & & \\
\hline Unchanged & $43(64.18)$ & $162(86.17)$ & $392(78.56)$ & $145(77.96)$ & & & \\
\hline Deteriorated & $11(16.42)$ & $5(2.66)$ & $10(2.00)$ & $8(4.30)$ & & & \\
\hline
\end{tabular}

revealed that female gender (OR 10.74, 95\% CI: 6.21-18.57, $p<0.01)$, anxiety symptoms (GAD-7) (OR 1.50, 95\% CI: $1.34-1.68, p<0.01)$, and decreased sexual satisfaction (OR 11.52, 95\% CI: 2.37-55.89, $p<0.01$ ) were risk factors related to poor couple relationship quality. However, high sexual activity frequency (OR 0.55, 95\% CI: $0.49-0.60, p<$ 0.01 ) and high income levels (OR 0.52, 95\% CI: 0.43-0.62, $p<0.01)$ were protective factors for high couple relationship quality (Table 6).

\section{Pathway analyses}

Pathway analyses indicated that GAD-7 $(\beta=-0.44, p<$ $0.01)$, PSS-14 $(\beta=-0.10, p<0.01)$, and factor $2(\beta=$ $-0.07, p<0.05)$ significantly, negatively predicted QMI.
However, the variable of factor $1(\beta=0.15, p<0.01)$ positively predicted the QMI (Table 7).

\section{Discussion}

This is the first study to report changes in sexual behaviour and couple relationship quality of patients with infertility during the lockdown. In this large-scale observational cross-sectional study, most of the participants reported no change in their sexual behaviour, anxiety symptoms, or couple relationship quality during lockdown; however, when we conducted a stratified analysis of the participants, significant differences were found between changes in sexual behaviour compared to different stress levels and couple 
Table 5 Changes in sexual behaviour, couple relationship, and anxiety symptoms of patients with infertility among different QMI score groups during lockdown $(n=940)$

\begin{tabular}{|c|c|c|c|c|c|}
\hline Items & $\begin{array}{l}\mathrm{QMI} \geq 34(n=296) \\
\text { mean } \pm \mathrm{SD} / n(\%)\end{array}$ & $\begin{array}{l}\mathrm{QMI}<34(n=644) \\
\text { mean } \pm \mathrm{SD} / n(\%)\end{array}$ & Statistics & Effect size $(d$ or $V)$ & $P$-value \\
\hline PSS-14 score & $34.68 \pm 10.83$ & $37.30 \pm 11.98$ & $t=-3.21$ & $d=-0.23$ & $<0.01$ \\
\hline Stress level & & & $\chi^{2}=2.53$ & $V=0.05$ & 0.47 \\
\hline Very high & $18(6.08)$ & $49(7.61)$ & & & \\
\hline High & $56(18.92)$ & $132(20.50)$ & & & \\
\hline General & $168(56.76)$ & $331(51.40)$ & & & \\
\hline Low or none & $54(18.24)$ & $132(20.50)$ & & & \\
\hline Changes in sexual satisfaction & & & $\chi^{2}=34.53$ & $V=0.19$ & $<0.01$ \\
\hline Increased & $27(9.12)$ & $16(2.48)$ & & & \\
\hline Unchanged & $262(88.51)$ & $565(87.73)$ & & & \\
\hline Decreased & $7(2.36)$ & $63(9.78)$ & & & \\
\hline Changes in sexual desire & & & $\chi^{2}=24.77$ & $V=0.16$ & $<0.01$ \\
\hline Increased & $24(8.11)$ & $22(3.42)$ & & & \\
\hline Unchanged & $260(87.84)$ & $540(83.85)$ & & & \\
\hline Decreased & $12(4.05)$ & $82(12.73)$ & & & \\
\hline Changes in sexual frequency & & & $\chi^{2}=22.88$ & $V=0.16$ & $<0.01$ \\
\hline Increased & $27(9.12)$ & $27(4.19)$ & & & \\
\hline Unchanged & $253(85.47)$ & $525(81.52)$ & & & \\
\hline Decreased & $16(5.41)$ & $92(14.29)$ & & & \\
\hline Changes in frequency of masturbation & & & $\chi^{2}=3.94$ & $V=0.07$ & 0.27 \\
\hline Decreased & $44(14.86)$ & $78(12.11)$ & & & \\
\hline Unchanged & $125(42.23)$ & $259(40.22)$ & & & \\
\hline Increased & $25(8.45)$ & $78(12.11)$ & & & \\
\hline None & $102(34.46)$ & $229(35.56)$ & & & \\
\hline Changes in frequency of pornography use & & & $\chi^{2}=5.72$ & $V=0.08$ & 0.13 \\
\hline Decreased & $25(8.45)$ & $55(8.54)$ & & & \\
\hline Unchanged & $112(37.84)$ & $199(30.90)$ & & & \\
\hline Increased & $18(6.08)$ & $58(9.01)$ & & & \\
\hline None & $141(47.64)$ & $332(51.55)$ & & & \\
\hline GAD-7 score & $5.66 \pm 1.92$ & $7.00 \pm 3.06$ & $t=-6.93$ & $d=-0.49$ & $<0.01$ \\
\hline COVID-19-related anxiety & & & $\chi^{2}=6.20$ & $V=0.08$ & $<0.05$ \\
\hline Extremely & $5(1.69)$ & $33(5.12)$ & & & \\
\hline Mildly & $67(22.64)$ & $144(22.36)$ & & & \\
\hline No & $224(75.68)$ & $467(72.52)$ & & & \\
\hline Changed in couple relationship during lockdown & & & $\chi^{2}=196.21$ & $V=0.46$ & $<0.01$ \\
\hline Better & $126(42.57)$ & $38(5.90)$ & & & \\
\hline Unchanged & $170(57.43)$ & $572(88.82)$ & & & \\
\hline Deteriorated & 0 & $34(5.28)$ & & & \\
\hline
\end{tabular}

relationship quality. The sexual activity frequency, anxiety symptoms, changes in sexual satisfaction during the lockdown, and income levels were all associated with couple relationship quality. Pathway analyses indicated that anxiety symptoms, stress levels, and changes in sexual behaviour can all predict the quality of couple relationship. Our findings are important, especially with respect to the consultations with patients with infertility.

Due to individual differences, context, and relational characteristics, people's stress responses to the pandemic vary. Some people lose interest in sex completely, whereas others show an increase in sexual desire and sexual activity frequency [18, 38-41]. In our study, the participants with high stress levels had significant perceived changes in sexual behaviour compared to those with low stress levels; we also observed a high incidence of decreases in sexual satisfaction, sexual desire, and sexual activity frequency in the very high stress level group compared to other groups. Evidence from national surveys of sexual life show that the decline in sexual 
Table 6 Factors related to couple relationship quality determined by the multivariate logistic regression analysis (low quality of couple relationship $=0$, high quality of couple relationship $=1$ )

\begin{tabular}{|c|c|c|c|c|c|c|}
\hline Items & $B$ & $S E$ & Wald & $O R$ & $95 \% C I$ & $P$-value \\
\hline Age & 0.00 & 0.02 & 0.01 & 1.00 & $0.96-1.05$ & 0.92 \\
\hline BMI & -0.02 & 0.03 & 0.35 & 0.99 & $0.94-1.04$ & 0.55 \\
\hline None-smoker & - & - & - & 1.00 & - & - \\
\hline Smoker & -0.36 & 0.28 & 1.67 & 0.70 & $0.41-1.20$ & 0.20 \\
\hline \multicolumn{7}{|l|}{ Gender } \\
\hline Male & - & - & - & 1.00 & - & - \\
\hline Female & 2.37 & 0.28 & 72.28 & 10.74 & $6.21-18.57$ & $<0.01$ \\
\hline Infertility duration & -0.01 & 0.04 & 0.02 & 1.00 & $0.92-1.07$ & 0.89 \\
\hline $\begin{array}{l}\text { Sexual life frequency } \\
\text { (per month) }\end{array}$ & -0.61 & 0.05 & 143.81 & 0.55 & $0.49-0.60$ & $<0.01$ \\
\hline Income levels & -0.66 & 0.09 & 50.90 & 0.52 & $0.43-0.62$ & $<0.01$ \\
\hline GAD-7 & 0.41 & 0.06 & 51.56 & 1.50 & $1.34-1.68$ & $<0.01$ \\
\hline PSS-14 & 0.01 & 0.01 & 1.58 & 1.01 & $0.99-1.03$ & 0.21 \\
\hline \multicolumn{7}{|c|}{ Changed in sexual desire } \\
\hline Increased & - & - & - & 1.00 & - & - \\
\hline Unchanged & 0.29 & 0.75 & 0.15 & 1.34 & $0.31-5.82$ & 0.70 \\
\hline Decreased & 0.59 & 0.93 & 0.40 & 1.80 & $0.29-11.08$ & 0.53 \\
\hline \multicolumn{7}{|c|}{ Changed in sexual frequency } \\
\hline Increased & - & - & - & 1.00 & - & - \\
\hline Unchanged & 0.13 & 0.68 & 0.04 & 1.14 & $0.30-4.29$ & 0.85 \\
\hline Decreased & 0.59 & 0.86 & 0.47 & 1.80 & $0.33-9.78$ & 0.49 \\
\hline \multicolumn{7}{|c|}{ Changed in sexual satisfaction } \\
\hline Increased & - & - & - & 1.00 & - & - \\
\hline Unchanged & 1.44 & 0.59 & 5.96 & 4.21 & $1.33-13.32$ & 0.02 \\
\hline Decreased & 2.44 & 0.81 & 9.19 & 11.52 & $2.37-55.89$ & $<0.01$ \\
\hline \multicolumn{7}{|c|}{ Changed in frequency of masturbation } \\
\hline None & - & - & - & 1.00 & - & - \\
\hline Increased & 0.28 & 0.56 & 0.25 & 1.32 & $0.44-3.91$ & 0.62 \\
\hline Unchanged & 0.42 & 0.29 & 2.01 & 1.52 & $0.85-2.69$ & 0.16 \\
\hline Decreased & -0.53 & 0.36 & 0.02 & 0.95 & $0.47-1.94$ & 0.88 \\
\hline \multicolumn{7}{|c|}{ Changed in frequency of pornography use } \\
\hline None & - & - & - & 1.00 & - & - \\
\hline Decreased & -0.41 & 0.42 & 0.01 & 0.96 & $0.43-2.17$ & 0.92 \\
\hline Unchanged & -0.08 & 0.28 & 0.07 & 0.93 & $0.53-1.61$ & 0.79 \\
\hline Increased & -0.31 & 0.64 & 0.24 & 0.73 & $0.21-2.57$ & 0.63 \\
\hline
\end{tabular}

activity frequency was related to increased use of pornography [42]. This supports our findings that pornography use increased among patients with high stress levels. Pornography use has increased worldwide during the COVID-19 pandemic [43]; it has been used mainly to relieve stress, loneliness, boredom, and other pandemicrelated negative emotions [44, 45]. The higher GAD-7 scores and a high rate of COVID-19-related anxiety reported among patients with high stress levels in our study also confirm this point.
Table 7 Model regression coefficients

\begin{tabular}{llllllll}
\hline$X$ & $\rightarrow$ & $Y$ & $\begin{array}{l}\text { Unstandard coef- } \\
\text { ficients }\end{array}$ & $S E$ & $Z(\mathrm{CR})$ & $p$ & $\begin{array}{l}\text { Standard } \\
\text { coeffi- } \\
\text { cients }\end{array}$ \\
\hline Factor2 & $\rightarrow$ & QMI & -0.23 & 0.09 & -2.49 & 0.01 & -0.07 \\
Factor1 & $\rightarrow$ & QMI & 0.95 & 0.19 & 5.08 & $<0.01$ & 0.15 \\
GAD-7 & $\rightarrow$ & QMI & -0.98 & 0.07 & -14.85 & $<0.01$ & -0.44 \\
PSS-14 & $\rightarrow$ & QMI & -0.06 & 0.02 & -3.59 & $<0.01$ & -0.10 \\
\hline
\end{tabular}


We found that female participants had lower QMI scores than male participants. A previous study reported that women have poorer couple relationship quality than men during the COVID19 pandemic, which is related to psychological distress [26]. Research also found that females have more psychological distress than males during the COVID-19 pandemic [46]. Investigations have shown that women experience higher levels of depression symptoms and other emotional distress related to infertility than men [47-49]. The aforementioned may explain why women had lower couple relationship quality than men in our study.

Higher rates of decreases in sexual satisfaction, sexual desire, and sexual activity were observed in patients with poor relationship quality than in those with high relationship quality. Furthermore, the logistic regression model revealed that the increases in the frequency of sexual activity and sexual satisfaction were protective factors for high relationship quality. This is consistent with the findings of Mollaioli et al. who also found that frequency of sexual activity can positively predict relationship quality [50] and was also confirmed in our pathway analysis.

Anxiety symptoms were a risk factor for poor relationship quality and negatively predicted QMI. The association between couple relationship quality and psychological health has been confirmed by several studies [51-53]. One study conducted during lockdown found that poor relationship quality led to a deterioration of mental health and well-being [54]. Another study also showed that couple relationship quality was related to mental health during the COVID-19 pandemic [27]; these studies support the connection that we have observed in patients with infertility.

Our research found that increased sexual desire, sexual activity frequency, and sexual satisfaction can positively predict couple relationship quality. The increased changes in sexual satisfaction are also a protective factor for couple relationship quality of patients with infertility and vice versa. The observed result is very interesting and meaningful because the sexual health of patients with infertility needs to be given more attention due to the societal implications of the condition. It is of great significance as this information can contribute to the improvement of treatment for patients with infertility, especially in times of crisis. The focus of future research should be on a longitudinal study to investigate infertility patients' sexual health, mental health, and couple relationship quality. Future studies should also aim to assess the influencing factors of couple relationship quality and sexual health of patients with infertility in a multi-centre controlled study.

\section{Strengths and limitations}

The strengths of our study are the large sample size of patients with infertility and that it investigates a sensitive topic of which there are currently few studies published. This is the first study to report changes in sexual behaviour and couple relationship quality of patients with infertility during the COVID-19 pandemic. Analysing factors that correlated with the quality of couple relationship, especially in times of crisis, is of great significance as this information can contribute to the improvement of treatment for patients with infertility.

The main limitation of our study is the cross-sectional study design. The results relied on participants self-reporting changes in their sexual behaviour; thus, any changes recorded were subject to recall bias. Furthermore, these participants may have been in a relationship that was not controlled; this may have introduced a bias to the results due to the dyadic interdependence of the outcomes. Further large-scale longitudinal studies are needed to understand the impact of the lockdown on changes in sexual behaviour in different types of patients with infertility.

\section{Conclusion}

Perceived changes in sexual behaviour with different stress levels and couple relationship quality were significantly different during the lockdown. Sexual activity frequency, changes in sexual satisfaction, anxiety symptoms, and income levels were closely related to couple relationship quality. Pathway analyses indicated that anxiety symptoms, stress level, and changes in sexual behaviour can all predict the quality of a couple's relationship. Analysing the factors that correlate with couple relationship quality, especially in times of crisis, is of great significance as this information can contribute to the improvement of treatment for patients with infertility.

Supplementary Information The online version contains supplementary material available at https://doi.org/10.1007/s10815-021-02361-4.

Acknowledgements Thanks to Mr. Xingchao Li for his language help in writing this manuscript and all staff of the Second Department of Reproductive Medicine, Shengjing Hospital of China Medical University, for their help in collecting the questionnaires.

Author contribution All authors have seen and approved the final version of this article. DM designed and executed the study, gathered, analysed and interpreted the data, drafted the manuscript, and contributed to the critical discussion. TYQ and WSS gathered, analysed and interpreted the data, drafted the manuscript, and contributed to the critical discussion. KL and ZFF contributed to the critical discussion. TJC acted as the supervisor, contributed to the study design, study execution, critical discussion, revised the manuscript, and approved the final submitted version.

Funding This study received a grant from the National Key Research and Development Program (2018YFC1004203), the Major Special Construction Plan for Discipline Construction Project of China Medical University (3110118033), and the Shengjing Freelance Researcher Plan of Shengjing Hospital of China Medical University. 
Availability of data and material The original data has been uploaded to the supplementary file.

Code availability Not applicable.

\section{Declarations}

Ethics approval The Hospital Institutional Review Board for Research on Human Subjects approved this study (2020PS009F).

Consent to participate All participants provided written informed consent.

Consent for publication All the authors in this paper consent to the publication of the work.

Conflict of interest The authors declare no competing interests.

\section{References}

1. Peter D. Covid-19 vaccine trial protocols released. BMJ. 2020;371:m4058. https://doi.org/10.1136/bmj.m4058.

2. Fore HH, Ghebreyesus TA, Watkins K, Greenslade L, Berkley S, Bassat Q, et al. Leveraging the COVID-19 response to end preventable child deaths from pneumonia. Lancet. 2020;396(10264):1709-11. https://doi.org/10.1016/S01406736(20)32348-5.

3. Walsh EE, Frenck RW, Falsey AR, Kitchin N, Absalon J, Gurtman A, et al. Safety and immunogenicity of two RNA-based Covid-19 vaccine candidates. N Engl J Med. 2020;383(25):2439-50. https:// doi.org/10.1056/NEJMoa2027906.

4. Ahmed MZ, Ahmed O, Aibao Z, Hanbin S, Siyu L, Ahmad A. Epidemic of COVID-19 in China and associated psychological problems. Asian J Psychiatr. 2020;51:102092. https://doi.org/10. 1016/j.ajp.2020.102092.

5. Capuano R, Altieri M, Bisecco A, d'Ambrosio A, Docimo R, Buonanno D, et al. Psychological consequences of COVID19 pandemic in Italian MS patients: signs of resilience? J Neurol. 2021;268(3):743-50. https://doi.org/10.1007/ s00415-020-10099-9.

6. Ćosić K, Popović S, Šarlija M, Kesedžić I, et al. Psychiatr Danub. 2020;32(1):25-31. https://doi.org/10.24869/psyd.2020.25.

7. Huang Y, Zhao N. Generalized anxiety disorder, depressive symptoms and sleep quality during COVID-19 outbreak in China: a webbased cross-sectional survey. Psychiatry Res. 2020;288:112954. https://doi.org/10.1016/j.psychres.2020.112954.

8. Shigemura J, Ursano RJ, Morganstein JC, Kurosawa M, Benedek DM. Public responses to the novel 2019 coronavirus (2019-nCoV) in Japan: mental health consequences and target populations. Psychiatry Clin Neurosci. 2020;74(4):281-2. https://doi.org/10.1111/pcn.12988.

9. Tian F, Li H, Tian S, Yang J, Shao J, Tian C. Psychological symptoms of ordinary Chinese citizens based on SCL-90 during the level I emergency response to COVID-19. Psychiatry Res. 2020;288:112992. https://doi.org/10.1016/j.psychres.2020. 112992.

10. Zhang SX, Wang Y, Rauch A, Wei F. Unprecedented disruption of lives and work: health, distress and life satisfaction of working adults in China one month into the COVID-19 outbreak. Psychiatry Res. 2020;288:112958. https://doi.org/10.1016/j. psychres.2020.112958.
11. Davison SL, Bell RJ, La CM, Holden SL, Davis SR. The relationship between self-reported sexual satisfaction and general well-being in women. J Sex Med. 2009;6(10):2690-7. https:// doi.org/10.1111/j.1743-6109.2009.01406.x.

12. Jacqueline $\mathrm{C}$, Shiong KFY, Helen B, Henrietta W, Jane T, Alaina $\mathrm{V}$, et al. Love during lockdown: findings from an online survey examining the impact of COVID-19 on the sexual health of people living in Australia. Sex Transm Infect. 2020;97(5):357-62. https://doi.org/10.1136/sextrans-2020-054688.

13. Ford JV, Corona V, Argas E, Finotelli I, Fortenberry JD, Kismödi E, Philpott A, et al. Why pleasure matters: its global relevance for sexual health. sexual rights and wellbeing. Int $\mathrm{J}$ Sex Health. 2019;31:217-30.

14. Turban JL, Keuroghlian AS, Mayer KH. Sexual Health in the SARS-CoV-2 Era. Ann Intern Med. 2020;173(5):387-9. https:// doi.org/10.7326/M20-2004.

15. Marta P, Roberta F, Angela C, Lilybeth F. Changes in sexuality and quality of couple relationship during the COVID-19 lockdown. Front Psychol. 2020;11:565823. https://doi.org/10.3389/ fpsyg.2020.565823.

16. Li W, Li G, Xin C, Wang Y, Yang S. Changes in sexual behaviors of young women and men during the coronavirus disease 2019 outbreak: a convenience sample from the epidemic area. J Sex Med. 2020;17:1225-8. https://doi.org/10.1016/j.jsxm.2020. 04.380.

17. Yasir ASM, Angi A-M, Kumar KS, Pawan S, Russell K. Does COVID-19 pandemic affect sexual behaviour? A cross-sectional, cross-national online survey. Psychiatry Res. 2020;289:113050. https://doi.org/10.1016/j.psychres.2020.113050.

18. Yuksel B, Ozgor F. Effect of the COVID-19 pandemic on female sexual behavior. Int J Gynaecol Obstet. 2020;150(1):98-102. https://doi.org/10.1002/ijgo.13193.

19. Baak Nora A, Cantineau AE, Cindy F, Brison Daniel R. Temperature of embryo culture for assisted reproduction. Cochrane Database Syst Rev. 2019;9:CD012192. https://doi.org/10.1002/ 14651858.CD012192.pub2.

20. Verhaak CM, Smeenk JMJ, Evers AWM, Kremer JAM, Kraaimaat FW, Braat DDM. Women's emotional adjustment to IVF: a systematic review of 25 years of research. Hum Reprod Update. 2007;13(1):27-36. https://doi.org/10.1093/humupd/dml040.

21. Pasch LA, Holley SR, Bleil ME, Dena S, Katz Patricia P, Adler Nancy E. Addressing the needs of fertility treatment patients and their partners: are they informed of and do they receive mental health services? Fertil Steril. 2016;106(1):209-215.e2. https://doi.org/10.1016/j.fertnstert.2016.03.006.

22. Ben-Kimhy R, Youngster M, Medina-Artom T, Avraham S, Gat I, Haham LM, et al. Fertility patients under COVID-19: attitudes, perceptions and psychological reactions. Hum Reprod. 2020;35(12):2774-83. https://doi.org/10.1093/humrep/deaa248.

23. Fabio B, La Rosa Valentina L, Vitale Salvatore G, Commodari $\mathrm{E}$, Altieri M, Scala C, et al. In vitro psychological status of infertile patients who had fertilization treatment interrupted or postponed due to COVID-19 pandemic: a cross-sectional study. J Psychosom Obstet Gynaecol. 2020; undefined 1-8. https://doi. org/10.1080/0167482X.2020.1853095.

24. Boivin J, Harrison C, Mathur R, Burns G, Pericleous-Smith A, Gameiro S. Patient experiences of fertility clinic closure during the COVID-19 pandemic: appraisals, coping and emotions. Hum Reprod. 2020;35(11):2556-66. https://doi.org/10.1093/humrep/ deaa218.

25. Ballester-Arnal R, Nebot-Garcia JE, Ruiz-Palomino E, GiménezGarcía C, Gil-Llario MD. "INSIDE" Project on sexual health in Spain: sexual life during the lockdown caused by COVID-19. Sex Res Soc Policy. 2020; undefined 1-19. https://doi.org/10.1007/ s13178-020-00506-1. 
26. Julianne H-L, Wendy B, Jones Brandon Q. Is there something unique about marriage? The relative impact of marital status, relationship quality, and network social support on ambulatory blood pressure and mental health. Ann Behav Med. 2008;35(2):239-44. https://doi.org/10.1007/s12160-008-9018-y.

27. Pieh C, O'Rourke T, Budimir S, Probst T. Relationship quality and mental health during COVID-19 lockdown. PLoS One. 2020;15(9):e0238906. https://doi.org/10.1371/journal.pone.02389 06.

28. Teo Alan R, Choi H, Valenstein M. Social relationships and depression: ten-year follow-up from a nationally representative study. PLoS One. 2013;8(4):e62396. https://doi.org/10.1371/journ al.pone. 0062396.

29. Löwe B, Decker O, Müller S, Brähler E, Schellberg D, Herzog $\mathrm{W}$, et al. Validation and standardization of the Generalized Anxiety Disorder Screener (GAD-7) in the general population. Med Care. 2008;46:266-74. https://doi.org/10.1097/MLR.0b013e3181 60d093.

30. Cohen S, Kamarck T, Mermelstein R. A global measure of perceived stress. J Health Soc Behav. 1983;4:385-96.

31. Maroufizadeh S, Almasi-Hashiani A, Amini P, Sepidarkish M, Omani-Samani R. The Quality of Marriage Index (QMI): a validation study in infertile patients. BMC Res Notes. 2019;12(1):507. https://doi.org/10.1186/s13104-019-4438-2.

32. Zimmermann T, de Zwaan M, Heinrichs N. The German version of the Quality of Marriage Index: psychometric properties in a representative sample and population-based norms. PLoS One. 2019;14(2):e0212758. https://doi.org/10.1371/journal.pone.0212758.

33. Rosseel Y. Lavaan: An R package for structural equation modeling. J Stat Softw. 2012;48(2):1-36. https://doi.org/10.18637/jss. v048.i02.

34. Bartlett MS. Tests of significance in factor analysis. Br J Stat Psychol. 1950;3(2):77-85. https://doi.org/10.1111/j.2044-8317. 1950.tb00285.x.

35. Lloret S, Ferreres A, Hernández A, Tomás I. The exploratory factor analysis of items: guided analysis based on empirical data and software. An de Psicol. 2017;33(2):417-32. https://doi.org/ 10.6018/analesps.33.2.270211.

36. Hair JF, Black WC, Babin BJ, Anderson RE, editors. Multivariate data analysis. 7th ed. Harlow: Pearson Education Limited; 2014.

37. Tabachnick BG, Fidell LS. Assumptions and limitations of multivariate statistical methods. In using multivariate statistics. 6th ed. Boston: Allyn and Bacon; 2013.

38. Dewitte M, Otten C, Walker L. Making love in the time of corona - considering relationships in lockdown. Nat Rev Urol. 2020;17(10):547-53. https://doi.org/10.1038/s41585-020-0365-1.

39. Fuchs A, Matonóg A, Pilarska J, Sieradzka P, Szul M, Czuba B, et al. The impact of COVID-19 on female sexual health. Int J Environ Res Public Health. 2020;17(19):7152. https://doi.org/10. 3390/ijerph17197152.

40. Ko NY, Lu WH, Chen YL, Li DJ, Chang YP, Wu CF, et al. Changes in sex life among people in Taiwan during the COVID19 pandemic: the roles of risk perception, general anxiety, and demographic characteristics. Int J Environ Res Public Health. 2020;17(16):E5822. https://doi.org/10.3390/ijerph17165822.

41. Li G, Tang D, Song B, Wang C, Qunshan S, Xu C, et al. Impact of the COVID-19 pandemic on partner relationships and sexual and reproductive health: cross-sectional, online survey study. J Med Internet Res. 2020;22(8):e20961. https://doi.org/10.2196/20961.

42. Wellings K, Palmer MJ, Machiyama K, Slaymaker E. Changes in, and factors associated with, frequency of sex in Britain: evidence from three National Surveys of Sexual Attitudes and Lifestyles (Natsal). BMJ. 2019;365:11525. https://doi.org/10.1136/bmj. 11525.

43. Mestre-Bach G, Blycker GR, Potenza MN. Pornography use in the setting of the COVID-19 pandemic. J Behav Addict. 2020;9(2):181-3. https://doi.org/10.1556/2006.2020.00015.

44. Bőthe B, Tóth-Király I, Potenza MN, Orosz G, Demetrovics Z. High-frequency pornography use may not always be problematic. J Sex Med. 2020;17(4):793-811. https://doi.org/10.1016/j.jsxm. 2020.01.007.

45. Camilleri C, Perry JT, Sammut S. Compulsive internet pornography use and mental health: a cross-sectional study in a sample of university students in the United States. Front Psychol. 2020;11:613244. https://doi.org/10.3389/fpsyg.2020.613244.

46. Gómez-Salgado J, Andrés-Villas M, Domínguez-Salas S, DíazMilanés D, Ruiz-Frutos C. Related health factors of psychological distress during the COVID-19 pandemic in Spain. Int J Environ Res Public Health. 2020;17(11):3947. https://doi.org/10.3390/ ijerph17113947.

47. Galhardo A, Cunha M, Pinto-Gouveia J, Matos M. The mediator role of emotion regulation processes on infertility-related stress. J Clin Psychol Med Settings. 2013;20(4):497-507. https://doi.org/ 10.1007/s10880-013-9370-3.

48. Peterson BD, Newton CR, Feingold T. Anxiety and sexual stress in men and women undergoing infertility treatment. Fertil Steril. 2007;88(4):911-4. https://doi.org/10.1016/j.fertnstert.2006.12. 023.

49. Zurlo MC, Cattaneo Della Volta MF, Vallone F. Factor structure and psychometric properties of the Fertility Problem InventoryShort Form. Health Psychol Open. 2017;4(2):2055102917738657. https://doi.org/10.1177/2055102917738657.

50. Daniele M, Andrea S, Giacomo C, Erika L, Elena C, Giorgio DL, et al. Benefits of sexual activity on psychological, relational, and sexual health during the COVID-19 breakout. J Sex Med. 2021;18(1):35-49. https://doi.org/10.1016/j.jsxm.2020.10.008.

51. Chapman B, Guven C. Revisiting the relationship between marriage and wellbeing: does marriage quality matter? J Happiness Stud. 2016;17:533-51. https://doi.org/10.1007/ s10902-014-9607-3.

52. Hsu T-L, Barrett AE. The association between marital status and psychological well-being: variation across negative and positive dimensions. J Fam Issues. 2020;41:2179-202. https://doi.org/10. 1177/0192513X20910184.

53. Leach LS, Butterworth P, Olesen SC, Mackinnon A. Relationship quality and levels of depression and anxiety in a large populationbased survey. Soc Psychiatry Psychiatr Epidemiol. 2013;48:41725. https://doi.org/10.1007/s00127-012-0559-9.

54. Pieh C, Probst T, Budimir S, Humer E. Associations between relationship quality and mental health during COVID-19 in the United Kingdom. Int J Environ Res Public Health. 2021;18(6):2869. https://doi.org/10.3390/ijerph18062869.

55. Gao J, Zhang X, Su P, Liu J, Shi K, Hao Z, et al. Relationship between sexual dysfunction and psychological burden in men with infertility: a large observational study in China. J Sex Med. 2013;10(8):1935-42. https://doi.org/10.1111/jsm.12207.

Publisher's note Springer Nature remains neutral with regard to jurisdictional claims in published maps and institutional affiliations. 